\title{
Características da Polpa kraft Extraída da Espécie Acácia-negra na Produção de Papel
}

\author{
Nelson Potenciano Marinho ${ }^{1}$, Umberto Klock², Elaine Cristina Lengowski², \\ Graciela Inês Bolzon de Muñiz²; Esoline Helena Cavalli Zamarian² \\ ${ }^{1}$ Departamento de Design, Centro Universitário Autônomo do Brasil - UniBrasil, Curitiba/PR, Brasil \\ ${ }^{2}$ Departamento de Engenharia e Tecnologia Florestal, Universidade Federal do Paraná - UFPR, Curitiba/PR, Brasil
}

\section{RESUMO}

Foram avaliadas as características da polpa kraft com branqueamento $(\mathrm{c} / \mathrm{b})$ e sem branqueamento (s/b) em diferentes tempos de refino da espécie Acacia mearnsii De Wild. A composição química mostrou baixas concentrações de lignina ácida insolúvel, extrativos totais e solubilidade em $\mathrm{NaOH}$ a $1 \%$. O rendimento bruto de $47,62 \%$ foi regular devido às características da fibra. O Kappa foi $4,5(\mathrm{c} / \mathrm{b})$ e $12,3(\mathrm{~s} / \mathrm{b})$, ambos baixos. O índice de drenabilidade $26^{\circ} \mathrm{SR}$ com T30' de refino (c/b) ficou próximo do ideal. Os maiores índices nas propriedades mecânicas foram: tração, com $66,17 \mathrm{~N} . \mathrm{m} / \mathrm{g}$ em T30' de refino s/b; rasgo, com $12,94 \mathrm{mN} \cdot \mathrm{m}^{2} / \mathrm{g}$ em T15' de refino c/b; estouro, com 5,21 KPa. $\mathrm{m}^{2} / \mathrm{g}$ em T30' de refino c/b, e nas propriedades ópticas, a alvura, com $81,8 \% \mathrm{em}$ T0' de refino c/b e opacidade em 97,1\%, com T0' de refino s/b. Com essas características, a espécie apresenta potencial para o setor na fabricação de papéis sanitários tissue, decorativos, dentre outros.

Palavras-chave: Acacia mearnsii De Wild, polpa celulósica, propriedades físico-mecânicas e ópticas.

\section{Characteristics of the Kraft Pulp Extracted from Black-Wattle Species in Papermaking}

\begin{abstract}
Were evaluated the characteristics of bleached (w/b) and unbleached $(\mathrm{u} / \mathrm{b}) \mathrm{Kraft}$ pulp at different refining times of the species acacia mearnsii De Wild. The chemical composition showed lower concentrations of insoluble lignin acid, total extractives and solubility in $\mathrm{NaOH}$ to $1 \%$. The raw yield of $47.62 \%$ was regular due to the fiber characteristics. The Kappa was 4.5 (w/b) and $12.3(\mathrm{u} / \mathrm{b})$, both considered low. The drainability index $26^{\circ} \mathrm{SR}$ with T30' refining $(\mathrm{w} / \mathrm{b})$ was near to ideal. The highest indexes in the mechanical properties were: tensile with $66.17 \mathrm{~N} . \mathrm{m} / \mathrm{g}$ in refining T30' (u/b); tear with $12.94 \mathrm{mN} . \mathrm{m}^{2} / \mathrm{g}$ in refining T15' $(\mathrm{w} / \mathrm{b})$; burst with $5.21 \mathrm{KPa} . \mathrm{m}^{2} / \mathrm{g}$ in refining $\mathrm{T} 30 \mathrm{~s}(\mathrm{w} / \mathrm{b})$ and the whiteness optical properties of $81.8 \%$ in refining $\mathrm{T} 0(\mathrm{w} / \mathrm{b})$ and opacity of $97.1 \%$ in refining $(\mathrm{u} / \mathrm{b})$. With these characteristic, the species has industry potential for the manufacturing of sanitary "tissue", decorative, among others papers.
\end{abstract}

Keywords: Acacia mearnsii De Wild, cellulosic pulp, physical-mechanical and optical properties. 


\section{INTRODUÇÃO}

Embora o eucalipto seja a principal fonte de matéria-prima para a produção de celulose de fibra curta no Brasil, a polpa de acácia vem ganhando mercado desde meados da década de 1990. Em outros países, em regiões como o Sudeste Asiático e África, a Acássia tem-se destacado como importante fonte de fornecimento de matéria-prima para a produção de celulose de fibra curta (Resende, 2001). Além de resultar em polpa celulósica com boas características para indústria de celulose (Segura et al., 2010), a acácia possui vantagens silviculturais, como ciclo de crescimento curto - e auxilia na recuperação de áreas degradadas como um importante fixador de nitrogênio no solo (Caldeira et al., 2002).

Segundo Boland et al. (1984), a Acacia mearnsii é uma espécie leguminosa originária do sudoeste da Austrália, popularmente conhecida como Acácia-negra. No Brasil, ela foi introduzida com a finalidade de produzir tanino, substância extraída da casca, produto básico para curtimento do couro, também utilizado na fabricação de adesivos, produtos farmacêuticos, dentre outros (Seiger, 2002; Fowler et al., 1999). De acordo com Foelkel (2008), cerca de 45 mil pequenos produtores no estado do Rio Grande do Sul estão envolvidos nessa cadeia produtiva - a espécie, juntamente com o eucalipto e o pinus, constitui expressivos plantios florestais no país. Os primeiros plantios comerciais foram realizados em 1928, no município de Estrela, RS, por meio de sementes (Boland et al., 1984). Atualmente, sua área plantada está em 148.311 hectares, em todo o país (ABRAF, 2013). A idade de corte da espécie varia de 5,5 a 10 anos e, na faixa de 6 a 8 anos, nos plantios brasileiros, apresenta rendimento de $246,6 \mathrm{~m}^{3} / \mathrm{ha}$, sendo que desse total $10 \%$ correspondem à casca. Aos 7 anos, a madeira apresenta uma densidade básica média entre 550 a $600 \mathrm{~kg} / \mathrm{cm}^{3}$ (Foelkel, 2008).

A madeira de A. mearnsii apresenta boa qualidade para a produção de polpa celulósica, apresentando menor teor de lignina, o que resulta em baixo consumo de produtos químicos para seu cozimento e branqueamento (Segura, 2012), além de propriedades ópticas e físico-mecânicas adequadas (Martinez, 2006). Segura et al. (2010) avaliaram três espécies de acácia (A. crassicarpa, A. mangium e A. mearnsii) com 6 anos. Os resultados mostraram que a espécie $A$. mearnsii é a que possui menor teor de lignina e maior teor de holocelulose e rendimento depurado. Sansigolo et al. (1986) e Petrik et al. (1984) avaliaram diversas espécies de acácia e concluíram que $A$. mearnsii demonstrou ser viável para a produção de celulose $\mathrm{kraft}$, sendo rica em hemicelulose, com alto teor de extrativos, baixo teor de lignina e densidade básica maior se comparada às outras madeiras comerciais para produção de celulose.

Diante do potencial da Acácia-negra, o presente estudo objetivou a produção de polpa celulósica pelo processo kraft e avaliou o rendimento e a qualidade de suas fibras nos diferentes tempos de refino, buscando identificar suas propriedades físicas, mecânicas e ópticas.

\section{MATERIAL E MÉTODOS}

\subsection{Preparação das amostras}

Utilizaram-se nesta pesquisa 12 árvores de Acácianegra da espécie Acacia mearnsii De Wild. com 8 anos de idade provenientes do município de Montenegro, região metropolitana de Porto Alegre, estado do Rio Grande do Sul. Foram coletadas seções transversais, no formato de discos, na altura do DAP (1,30 m). De cada disco foram extraídas 5 amostras para diversas análises. Transformada em cavacos, a madeira foi seca ao ar até atingir umidade de equilíbrio (20\%) e uma parte foi convertida em serragem para análise química por meio de um moinho de faca tipo Willey. A serragem obtida foi classificada em peneiras de 40 e 60 mesch, sendo utilizada a fração retida na peneira de 40 mesch.

Os procedimentos analíticos da madeira e da polpa foram realizados de acordo com os métodos apresentados na Tabela 1.

Tabela 1. Procedimentos para preparação e análise da madeira.

Table 1. Procedures for preparation and analysis of Wood.

\section{Métodos}

Procedimentos

Preparação da madeira para análise química

TAPPI T-264 cm-97

Extrativos totais da madeira TAPPI T-204 cm-97

Solubilidade em $\mathrm{NaOH}$ a $1 \%$ TAPPI T-212 om-02

Lignina insolúvel em ácido (madeira)

TAPPI T-222 om-98

Densidade básica da madeira
TAPPI T-258 om-94

ABNT (NBR 11941) 


\subsection{Processo de obtenção da polpa celulósica de Acácia-negra pelo processo kraft}

A obtenção da polpa celulósica foi realizada em digestor rotativo de aço inoxidável composto por quatro cápsulas internas, aquecido eletricamente e dotado de sistema de controle de tempo e temperatura automático. Para a titulação do licor adotaram-se as recomendações da norma T624 cm-00. Para avaliação do teor de sólidos totais foram recolhidas amostras do licor negro residual. Para determinação gravimétrica do teor de sólidos totais utilizou-se a norma T650-om 89. As condições de cozimento estão enunciadas na Tabela 2.

Após cozimento da polpa celulósica, o material foi desagregado utilizando-se desfibrador de discos (tipo Bauer) e lavado em baixa consistência, 0,65\%, até remoção completa do licor negro residual, centrifugado e acondicionado em sacos plásticos.

O experimento teve como finalidade obter polpas otimizadas com baixos índices de lignina residual, ideal para produção de polpa branqueada, com Kappa objetivo de $16 \pm 2$.

As polpas celulósicas obtidas passaram pelo processo de refino utilizando-se o moinho tipo Jokro-Mühle, a $150 \mathrm{rpm}$ e seguindo-se as recomendações da norma ISO 5264/3 (ISO, 1979). A consistência foi de $6 \%$ à temperatura de $30{ }^{\circ} \mathrm{C}$, com os tempos de 15 (T15') e 30 (T30') minutos. O processo de refino foi conduzido visando conhecer a característica do material. A determinação do grau de refinação ou grau de drenabilidade da polpa celulósica foi realizada no equipamento denominado Schopper-Riegler ( ${ }^{\circ} \mathrm{SR}$ ), normatizado pela ISO 5267/1 (ISO, 1999).

Foram formadas 5 folhas circulares de papel sem branqueamento $(\mathrm{s} / \mathrm{b})$ e branqueadas $(\mathrm{c} / \mathrm{b})$ sem refino (T0') e com refinos em T15' e T30', com gramatura de aproximadamente $60 \pm 2 \mathrm{~g} / \mathrm{m}^{-2}$, utilizando-se uma estação formadora tipo Rapid-Köethen dotada de dois secadores a uma temperatura de $90 \pm 2{ }^{\circ} \mathrm{C}$ e a uma pressão aplicada em torno de $80 \mathrm{KPa}$. Essas amostras foram acondicionadas em ambiente climatizado a uma temperatura de $23 \pm 2{ }^{\circ} \mathrm{C}$ e $50 \pm 2 \%$ de umidade relativa do ar.

As folhas passaram por ensaios físicos, mecânicos e ópticos segundo procedimentos e métodos padronizados de acordo com normas técnicas da Technical Association of the Pulp and Paper Industry (TAPPI, 2005), conforme indicado na Tabela 3.

O branqueamento foi realizado em quatro etapas, conforme os parâmetros demonstrados na Tabela 4 .

\section{RESULTADOS E DISCUSSÃO}

\subsection{Composição química}

Os resultados na composição química da Acácia-negra mostraram: lignina ácida insolúvel com 19,56\%; extrativos totais, $2,0 \%$; e solubilidade em $\mathrm{NaOH}$ a $1 \%, 11,5 \%$. Nas análises de Segura et al. (2010) foram: 72,26\% de holocelulose; 20,27\% para lignina ácida insolúvel; extrativos totais, $4,25 \%$. Martins (1983) obteve para a mesma espécie, $80,16 \%$ de holocelulose; $19,75 \%$ de lignina ácida insolúvel; extrativos totais, 5,23\%; e $\mathrm{NaOH}$ a $1 \%, 14,7 \%$, e ainda destaca que os dois últimos componentes afetam negativamente, uma vez que serão solubilizados, em sua maior parte, no cozimento kraft e isso afetará o rendimento final.

Foelkel (2008) apresenta algumas estimativas usuais da composição química da Acácia-negra plantada no Brasil para uso industrial: lignina na faixa de $18,8 \%$ a $19,6 \%$ e solubilidade em $\mathrm{NaOH}$ a $1 \%$ entre $14,8 \%$ e $17,3 \%$.

\subsection{Densidade básica da madeira e o rendimento bruto da polpa}

A densidade básica é um importante parâmetro na avaliação da qualidade da madeira para a produção de polpa celulósica, fornecendo indicações bastante precisas sobre os níveis de impregnação dos cavacos

Tabela 2. Condições de cozimento da Acácia-negra no processo kraft.

Table 2. Cooking conditions in the Kraft process of acacia black.

\begin{tabular}{|c|c|c|c|c|c|c|c|c|}
\hline Espécie & Massa base seca (g) & $\begin{array}{l}\text { AA } \\
(\%)\end{array}$ & $\begin{array}{c}\text { S } \\
(\%)\end{array}$ & RLM & $\begin{array}{c}\mathrm{T} \\
\left({ }^{\circ} \mathrm{C}\right)\end{array}$ & $\begin{array}{c}\text { TMx } \\
(\mathrm{min})\end{array}$ & $\begin{array}{l}\text { TMxC } \\
(\min )\end{array}$ & F H \\
\hline Acacia mearnsii & 1000 & 20 & 25 & $4: 1$ & 170 & 119 & 60 & 1100 \\
\hline
\end{tabular}

$\mathrm{AA}=$ álcalis-ativo; $\mathrm{RLM}=$ relação licor/madeira; $\mathrm{T}$ = temperatura; $\mathrm{TMx}=$ tempo até ser atingida a temperatura máxima de cozimento; $\mathrm{TMxC}=$ tempo na temperatura máxima de cozimento. 
e do rendimento do processo. Geralmente, essa característica da madeira está associada à qualidade e resistência físico-mecânica da polpa.

Os resultados obtidos neste estudo mostram que a densidade básica dos cavacos de Acácia-negra aos 8 anos de idade foi de $531 \mathrm{~kg} / \mathrm{m}^{3}$. Sansigolo et al.

Tabela 3. Análises e procedimentos para ensaios físicos, mecânicos e ópticos.

Table 3. Analyzes and procedures for physical, mechanical and optical tests.

\begin{tabular}{|c|c|}
\hline Análises & Procedimentos \\
\hline $\begin{array}{l}\text { Determinação da } \\
\text { drenabilidade }\end{array}$ & $\begin{array}{l}\text { TAPPI T- } 460 \text { om- } 02 \text { e } \\
\text { ISO 5267/1 }\end{array}$ \\
\hline $\begin{array}{l}\text { Formação das folhas de } \\
\text { papel }\end{array}$ & $\begin{array}{l}\text { TAPPI T- } 402 \text { om-94 e } \\
\text { ISO } 5269 / 2\end{array}$ \\
\hline Gramatura $^{(1)}$ & TAPPI T-410 om-02 \\
\hline $\begin{array}{l}\text { Teor de umidade das folhas } \\
\text { de papel }\end{array}$ & TAPPI T-412 om-02 \\
\hline $\begin{array}{l}\text { Espessura das folhas de } \\
\text { papel }\end{array}$ & TAPPI T-411 om-97 \\
\hline Resistência a tração ${ }^{(2)}$ & TAPPI T-494 om-01 \\
\hline Resistência ao rasgo $^{(3)}$ & TAPPI T-414 om-98 \\
\hline $\begin{array}{l}\text { Resistência do papel ao } \\
\text { estouro }^{(4)}\end{array}$ & TAPPI T-403 om-02 \\
\hline Opacidade $^{(5)}$ & TAPPI T-429 om-01 \\
\hline Alvura $^{(5)}$ & TAPPI T-452 om-08 \\
\hline $\begin{array}{l}\text { Determinação do número } \\
\text { Kappa }\end{array}$ & TAPPI T-236 om-99 \\
\hline \multicolumn{2}{|c|}{$\begin{array}{l}\text { (1)Ensaio de espessura produzido em um medidor de espessura } \\
\text { marca Regmed, no qual se obteve a gramatura. }{ }^{(2)} \text { Ensaio } \\
\text { de tração realizado em equipamento marca Regmed tipo } \\
\text { RE/A30. }{ }^{(3)} \text { Ensaio de rasgo (aparelho tipo pêndulo Elmendorf) } \\
\text { foi realizado em equipamento marca Regmed tipo ED-1600. } \\
\text { (4) Ensaio de estouro foi feito em equipamento Müllen test } \\
\text { marca Regmed MT/Mot-A. }{ }^{(5)} \text { Ensaio de opacidade e alvura } \\
\text { foi feito em equipamento marca Regmed tipo AL/OP-DIG } \\
\text { (nível de reflectância direcional em } 457 \mathrm{~nm} \text { ). }\end{array}$} \\
\hline
\end{tabular}

(1986) em sua pesquisa, obteveram $621 \mathrm{~kg} / \mathrm{m}^{3}$ para exemplares de 7 anos de idade.

Foelkel (2008) descreve sobre as características anatômicas das fibras de Acácia-negra que possuem elementos de vasos de pequeno comprimento e diâmetro, maior fração de parede, vasos concentrados e menos dispersos, parênquima radial delgado e mal distribuído na seção longitudinal, menor diâmetro do lúmen e paredes mais espessas das fibras, raios medulares e vasos distantes uns dos outros, além de maior densidade básica da madeira. Tais particularidades afetam e interferem na qualidade da polpa e no rendimento.

O processo kraft é mundialmente adotado, pois apresenta algumas vantagens. Dentre elas, a possibilidade de remoção de grande parte da lignina contida na matriz celulósica em ciclo curto de cozimento, eficiência na recuperação de reagentes, além de polpas branqueadas a altos níveis de alvura (Silva et al., 2009; Costa, 2011). Outro aspecto a ser considerado é o rendimento decorrente da solubilização de grande parte dos componentes da fibra, ou seja, no processo são dissolvidos cerca de $80 \%$ da lignina, $50 \%$ da hemicelulose e $10 \%$ da celulose (Sanjuan, 1997). Pois um menor teor de lignina pode resultar em menor consumo de produtos químicos durante o cozimento e em tempos mais curtos de digestão (Foelkel, 1993). Contudo, a lignina que permanece na celulose após as operações de conversão torna a fibra mais rígida, resultando em papéis de baixa resistência e alta opacidade (Martinez, 2006).

$\mathrm{O}$ rendimento bruto alcançado neste estudo foi de $47,62 \%$ com percentual de álcalis ativos de $20 \%$.

Tabela 4. Etapas de branqueamento.

Table 4. The bleaching stage.

\begin{tabular}{|c|c|c|c|c|}
\hline \multirow[b]{2}{*}{$\begin{array}{l}\text { Parâmetros do branquea- } \\
\text { mento }\end{array}$} & $1^{\text {a }}$ Etapa & $2^{\mathrm{a}}$ Etapa & $3^{\text {a }}$ Etapa & $4^{\text {a }} \operatorname{Etapa}^{(*)}$ \\
\hline & $\begin{array}{c}\text { Dióxido de cloro } \\
\left(\mathrm{CLO}_{2}\right) \\
20 \mathrm{~g} / \mathrm{L}\end{array}$ & $\begin{array}{l}\text { Peróxido de } \\
\text { hidrogênio } \\
\qquad\left(\mathrm{H}_{2} \mathrm{O}_{2}\right)\end{array}$ & $\begin{array}{l}\text { Dióxido de cloro } \\
\qquad\left(\mathrm{CLO}_{2}\right)\end{array}$ & $\begin{array}{c}\text { Peróxido de } \\
\text { hidrogênio } \\
\left(\mathrm{H}_{2} \mathrm{O}_{2}\right)\end{array}$ \\
\hline Quantidade (\%) & $2 \%^{(* *)}$ & 0,5 & $2 \%^{(* * *)}$ & 0,3 \\
\hline Temperatura $\left({ }^{\circ} \mathrm{C}\right)$ & 90 & 90 & 90 & 90 \\
\hline Tempo (min.) & 60 & 60 & 60 & 60 \\
\hline Consistência (\%) & 10 & 10 & 10 & 10 \\
\hline $\mathrm{NaOH}(\%)$ & - & $1 \%$ & - & 0,6 \\
\hline $\mathrm{MgSO}_{4}(\%)$ & - & - & - & 0,3 \\
\hline Tampão (Buffer) (ml) & $100 \mathrm{ml}$ & - & $10 \mathrm{ml}$ & - \\
\hline
\end{tabular}

(*) $\mathrm{Na}$ última etapa foi adicionado sulfato de magnésio $\left(\mathrm{MgSO}_{4}\right)$, com a finalidade de reduzir o consumo de peróxido de hidrogênio $\left(\mathrm{H}_{2} \mathrm{O}_{2}\right) .{ }^{(*)}$ Equivalente a $100 \mathrm{ml} .{ }^{(* *)}$ Equivalente a $10 \mathrm{ml}$. 
Balodis (1991) classifica esse resultado de rendimento como regular e de percentual de álcalis ativo elevado. Foelkel (2008) estima um rendimento bruto na faixa de 53,5\% para a espécie Acacia mearnsii aos 7 anos. Um rendimento bruto superior de $57 \%$ com cargas de álcalis de $20,8 \%$ em temperatura de $170{ }^{\circ} \mathrm{C}$ foi alcançado por Segura et al. (2010) para Acácia-negra de 6 anos, com densidade básica de $516 \mathrm{~kg} / \mathrm{cm}^{3}$. Fang et al. (1991) também obteveram 49,9\% de rendimento com Acácia-negra de 10 anos e densidade de $608 \mathrm{~kg} / \mathrm{m}^{3}$ com 13\% de cargas de álcalis ativos. Resende (2001) explicam que dentre as espécies tropicais e subtropicais concorrentes, como A. dealbata, A. decurrens e A. Silvestris, a Acácia-negra (A.mearnsii) sobressaiu-se pela produtividade de celulose em torno de $315 \mathrm{~kg} / \mathrm{m}^{3}$ e alta densidade, em torno de $600 \mathrm{~kg} / \mathrm{m}^{3}$.

Quanto ao teor de sólidos residuais, foram apurados $17,27 \%$, valor referente à quantidade de licor branco e outros componentes. Stein (2010) descreve essa composição como sendo hidróxido de sódio $(\mathrm{NaOH})$, sulfeto de sódio $\left(\mathrm{Na}_{2} \mathrm{~S}\right)$, formando os álcalis ativos, e outros tipos de sais de sódio, em pequenas quantidades, como carbonato de sódio $\left(\mathrm{Na}_{2} \mathrm{CO}_{3}\right)$, que não reagiram, somados à lignina dissolvida, extrativos e carboidratos que foram retirados durante o processo de cozimento.

\subsection{Indice de drenabilidade}

Essa propriedade é evidenciada pelo efeito mecânico a que a polpa celulósica é submetida no decorrer do refino e pela presença de lignina residual. Observando-se os resultados das Tabelas 5 e 6 é possível inferir que o refino melhora o grau de drenabilidade mesmo em polpa com maior teor de lignina.

Em relação às características das fibras de Acácia-negra, Martins (1983) encontrou elevados valores para fração parede (47,9\%), os quais indicam fibras mais rígidas e que deverão produzir folha com elevado volume aparente, porosidade, opacidade e boa capacidade de absorção. Foelkel (2008) explica que essas fibras, quando sem refino, são mais rígidas e que nos estágios iniciais de refino apresentam dificuldade para ganhar resistência, opondo-se à elevação do grau de refinação, e desse modo apresentam menores índices de drenabilidade ( $\left.{ }^{\circ} \mathrm{SR}\right)$, como pode ser observado na Tabela 5.

Comumente, as empresas do setor papeleiro adotam $25^{\circ} \mathrm{SR}$, faixa na qual os ganhos e perdas de propriedades mecânicas ficam em patamares intermediários, sem
Tabela 5. Índice de drenabilidade nos diferentes tempos de refino da polpa de Acácia-negra.

Table 5. Drainability index of different times refining pulp from black-wattle.

\begin{tabular}{|cc|}
$\begin{array}{c}\text { Tempo de refino } \\
\text { (min.) }\end{array}$ & $\begin{array}{c}\text { Indice de drenabilidade } \\
\left({ }^{\circ} \mathbf{S R}\right)\end{array}$ \\
\hline T 0' s/b & $\mathbf{1 8 , 5}$ \\
T 15' s/b & $\mathbf{2 3 , 5}$ \\
\hline T 30' s/b & $\mathbf{2 8 , 0}$ \\
T 0' c/b & $\mathbf{1 7 , 0}$ \\
T 15' c/b & $\mathbf{2 2 , 5}$ \\
T 30' c/b & $\mathbf{2 6 , 0}$ \\
\hline
\end{tabular}

T0' s/b = tempo de refino de 0 minutos sem branqueamento; $\mathrm{T} 15^{\prime} \mathrm{s} / \mathrm{b}=$ tempo de refino de 15 minutos sem branqueamento; $\mathrm{T} 30$ ' $\mathrm{s} / \mathrm{b}=$ tempo de refino de 30 minutos sem branqueamento $\mathrm{T} 0^{\prime} \mathrm{c} / \mathrm{b}=$ tempo de refino de 0 minutos com branqueamento $\mathrm{T} 15^{\prime} \mathrm{c} / \mathrm{b}=$ tempo de refino de 15 minutos com branqueamento $\mathrm{T} 30^{\prime} \mathrm{c} / \mathrm{b}=$ tempo de refino 30 minutos com branqueamento.

Tabela 6. Número Kappa extraído da polpa de Acácianegra após cozimento e depois da primeira etapa de branqueamento.

Table 6. Kappa number extracted from Brack-Wattle pulp after cooking and after first bleaching.

\begin{tabular}{cc|}
\hline Etapa & Número Kappa \\
\hline Polpa $\mathrm{s} / \mathrm{b}$ & 12,3 \\
\hline Polpa $\mathrm{c} / \mathrm{b}^{(*)}$ & 4,5 \\
\hline $\mathrm{s} / \mathrm{b}=$ sem braqueamento; $\mathrm{c} / \mathrm{b}=$ com branqueamento. ${ }^{(*)}$ Número
\end{tabular}

Kappa extraído somente após a $1^{\mathrm{a}}$ etapa de branqueamento.

considerar o fator gasto energético para produção da polpa. Observando-se a Tabela 5 é possível afirmar que o resultado mais próximo a esse índice foi $26^{\circ} \mathrm{SR}$ com T30' de refino nas polpas branqueadas.

\subsection{Determinação do número Kappa}

A determinação do número Kappa indica o grau de deslignificação ou a quantidade de lignina residual que ainda permanece na polpa após o cozimento, sendo a sua estimativa fundamental para quantificação do consumo de reagentes nos processos de branqueamento, avaliação da qualidade da madeira e da eficiência do processo de polpação (Segura et al., 2010).

Nas condições de cozimento empregadas neste estudo (Tabela 2) e nas etapas de branqueamento (Tabela 4) observaram-se baixos índices de lignina residual presentes na polpa. A Tabela 6 apresenta o número Kappa extraído da polpa celulósica de Acácia-negra após o cozimento e depois da primeira etapa de branqueamento. 
Analisando-se a Tabela 6 é possível inferir que após a primeira etapa de branqueamento (Tabela 4 ) houve uma remoção acentuada de lignina, reduzindo-se em $63 \%$ a lignina residual ainda presente na polpa após o cozimento.

\subsection{Propriedades do papel}

\subsubsection{Propriedades físicas do papel}

Analisando-se a Figura 1a - espessura do papel e Figura 1c - volume aparente, observa-se que, de modo geral, seus índices diminuem gradualmente com o aumento do tempo de refino. Isso decorre da diminuição da espessura das paredes celulares e quebra da rigidez das fibras. Foelkel (2009) explica que folhas volumosas apresentam algumas desvantagens, pois
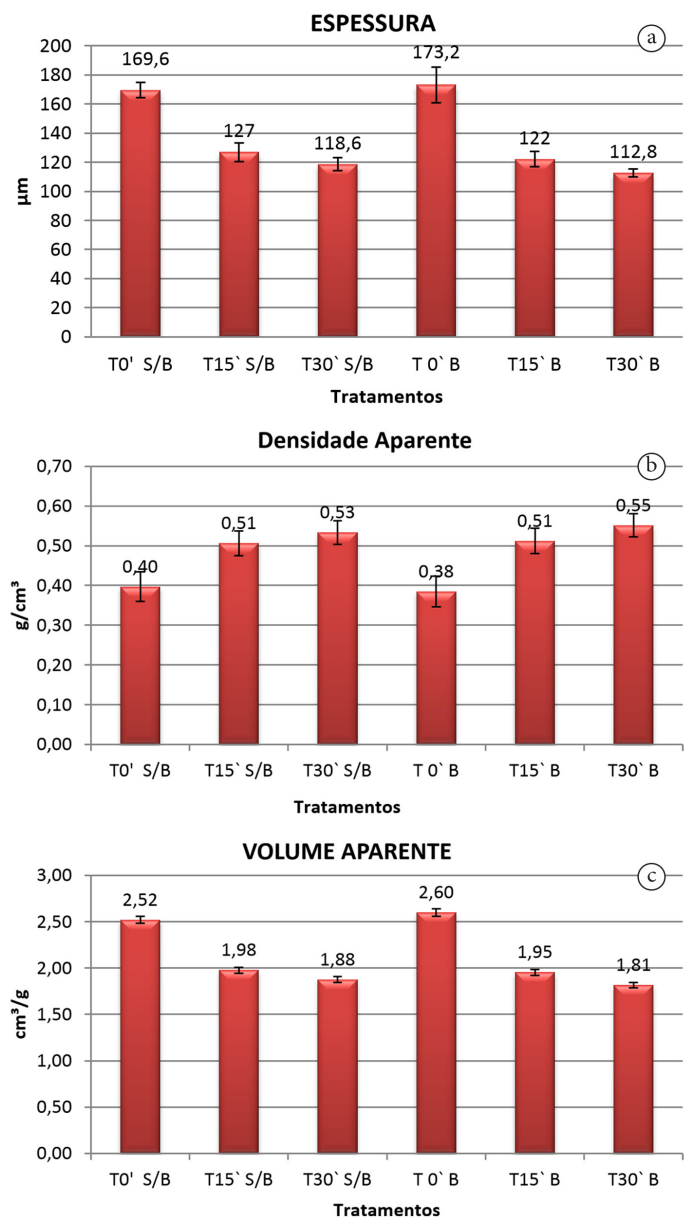

Figura 1. (a) Espessura; (b) Densidade aparente; (c) Volume aparente.

Figure 1. (a) Thickness; (b) apparent density; (c) apparent measure. quanto maior o seu volume mais porosa tendem a ficar, ou seja, apresentam menor ligação entre as fibras, consequentemente, baixa densidade, originando papel com baixa resistência.

A densidade básica da madeira é um parâmetro que se relaciona diretamente com a característica das fibras da espécie. Tendo a Acácia-negra fibras com elevados índices de espessura de parede e fração parede, resultaria em menor volume de fibras necessário para determinada massa de celulose. No entanto, o consumo específico aumenta com o grau de deslignificação e com o tempo de refino (Segura et al., 2010).

\subsection{Propriedades mecânicas}

O aumento da resistência do papel ocorre devido às modificações na estrutura das paredes celulares das fibras (colapso), decorrentes da ação mecânica do refino. Segundo Foelkel (2008), elevado teor de hemicelulose na composição da Acácia-negra torna mais fácil suas paredes colapsarem durante a refinação da massa, conferindo maior flexibilidade e plasticidade no decorrer do processo, o que se reflete nas propriedades mecânicas.

O processo de desfibrilamento da parede celular cria sítios de ligações hidrofílicas no seu interior, as quais absorvem moléculas de água, tornando-a mais flexível, e confere a ela habilidade de se conformar uma sobre a outras, criando maior superfície de adesão e aumentado, assim, a força de ligação interfibras (Manfredi, 2010).

A resistência à tração e ao arrebentamento são fortemente influenciadas pelo comprimento das fibras e, principalmente, pelos efeitos mecânicos advindos do processo de refino, quando há o colapsamento da parede celular, que as torna mais maleáveis, aumentando assim sua área de contato (Biermann,1996), e por consequência a formação de folhas mais densas (Scott et al., 1995; Ferreira, 2008). Por serem as paredes das fibras da Acácia-negra mais espessas e pesadas (densas), apresentam comportamento distinto das demais fibras comerciais, como do eucalipto e do pinus.

Neste estudo foi observado que houve um aumento na propriedade de tração (Figura 2a) de 40,93 N.m/g entre as polpas com T0' e T30' de refino (s/b) e de 47,37 N.m/g entre as polpas com T0' e T30' de refino $(\mathrm{c} / \mathrm{b})$. O aumento da resistência à tração para polpa branqueada em relação à não branqueada se deve 

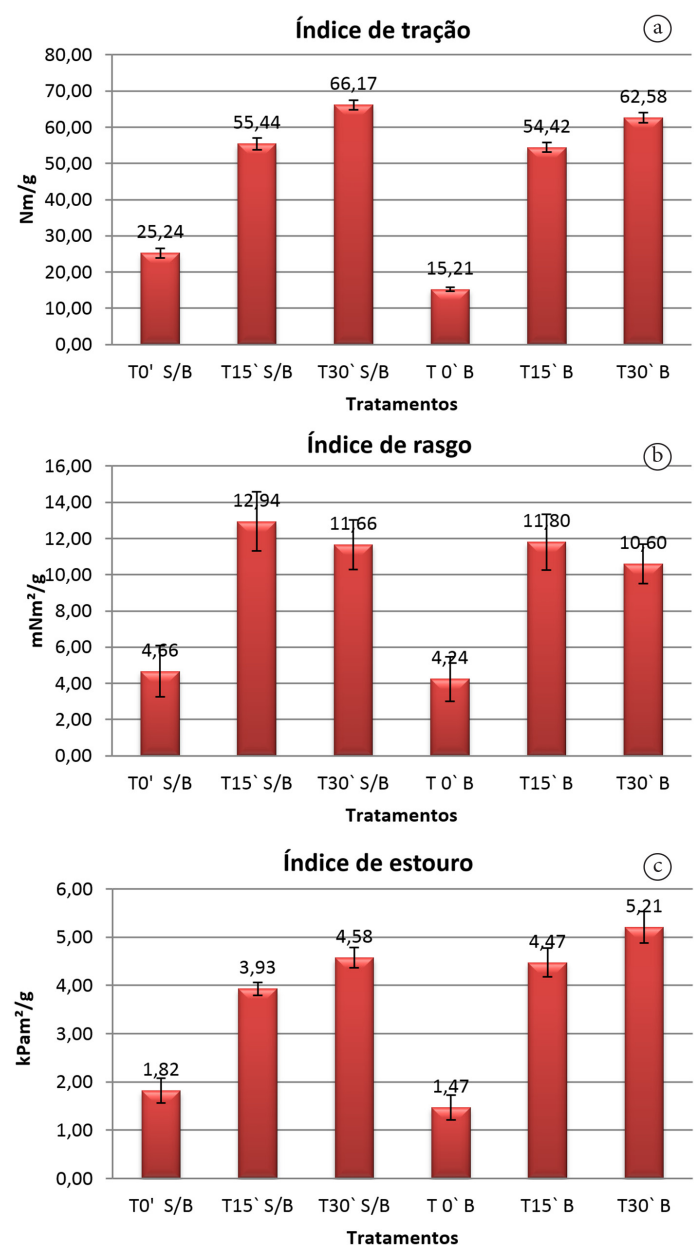

Figura 2. (a) Îndice de tração; (b) Índice de rasgo; (c) Índice de estouro.

Figure 2. (a) Tensile index; (b) Tear index; (c) Burst index.

ao fato de as fibras estarem mais flexíveis, devido ao menor teor de lignina, o que acaba levando a maior fibrilamento no momento do refino. Segundo Da Rosa (2003), o grau de deslignificação reflete nas propriedades da polpa, bem como sobre sua resistência individual, ou na estrutura consolidada das fibras na folha de papel. O efeito do tempo de refino produz um grau de desprendimento total ou parcial das camadas das paredes primária e secundária, liberando finos lamelares e fibrilares e aumentando a força de ligação entre as fibras (Biermann, 1996). Essas microdesfibrilações resultam em aumento da área superficial de adesão e de contato entre as superfícies das paredes celulares, tornado as folhas mais flexíveis e densas (Nevell \& Zeronian, 1985). Segura et al. (2010) obteve resultados superiores nos índices de tração, cerca de $98 \mathrm{Nm} / \mathrm{g}^{-1}$ em polpa c/b com menor tempo de refino para acácia com 6 anos e Sansigolo et al. (1986). 86,26 Nm/g $/ \mathrm{g}^{-1} \mathrm{em}$ polpa s/b.

O índice de estouro apresentou comportamento semelhante à propriedade de tração (Figura 2c). Seu aumento decorre do colapsamento das fibras, que as torna mais flexíveis. Segundo Klock (2000), essa propriedade cresce com o grau de refino, até certo limite, e passa a decrescer gradativamente quando o excede. Assim, o aumento da plasticidade das fibras obtido por meio da refinação acontece até o ponto no qual as fibras não são degradadas. Fang et al. (1991) realizaram ensaios de estouro em polpa c/b na sequência CEHD e obteveram $4,5 \mathrm{kPa} \cdot \mathrm{m}^{2} / \mathrm{g}^{-1}$ para A. mearnsii de 10 anos com densidade de $608 \mathrm{~kg} / \mathrm{m}^{3}$; Sansigolo et al. (1986), foi 5,38 $\mathrm{kPa} \cdot \mathrm{m}^{2} / \mathrm{g}^{-1}$ para polpas s $/ \mathrm{b}$ com 7 anos de idade com densidade de $621 \mathrm{~kg} / \mathrm{m}^{3}$.

Alguns fatores influenciam a resistência ao rasgo, dentre eles comprimento e espessura da parede celular, rigidez, quantidade de fibras e resistência entre suas ligações (D’Almeida, 1988). A refinação de modo geral colabora com a melhoria das ligações entre fibras, porém diminui a resistência individual. Assim, o rasgo depende da resistência individual das fibras e não varia proporcionalmente com a resistência à tração ou estouro, sendo uma função do grau de refino das fibras - entretanto, em determinado ponto começa a decair (Sanjuan, 1997). Na fase inicial do refino, a folha tende a oferecer menor resistência ao rasgo devido às ligações entre as fibras serem mais fracas (Figura 2b), ou seja, torna-se mais fácil arrebentar a folha pela quebra das ligações ao invés da ruptura das fibras, o que não ocorre com maior tempo de refino (Klock, 2000).

Pode-se observar que o índice de rasgo (Figura $2 \mathrm{~b}$ ) apresentou um aumento significativo em T15' de refino e começou a diminuir em T30' de refino em polpas $\mathrm{s} / \mathrm{b}$ e c/b. Fang et al. (1991), analisando índice de rasgo em polpas $\mathrm{kraft} \mathrm{c} / \mathrm{b}$ na sequência CEHD de acácia de 10 anos, obteveram 7,5 $\mathrm{mN} \cdot \mathrm{m}^{2} / \mathrm{g}^{-1}$. Sansigolo et al. (1986), para a mesma propriedade, obteveram $11,14 \mathrm{mN} \cdot \mathrm{m}^{2} / \mathrm{g}^{-1}$ para polpa s/b de Acácia-negra com 7 anos.

\subsection{Propriedades ópticas de opacidade e alvura}

As propriedades de alvura e opacidade (Tabela 7) são importantes para determinação da aplicação do papel. As tecnologias de branqueamento visam a retirada dos 
Tabela 7. (a) Alvura; (b) Opacidade.

Table 7. (a) Whiteness; (b) Opacity.

\begin{tabular}{cccccc} 
Tempo de & \multicolumn{2}{c}{ Alvura (ISO) } & & \multicolumn{3}{c}{ Opacidade (\%) } \\
\cline { 2 - 3 } $\begin{array}{c}\text { refino } \\
\text { (minutos) }\end{array}$ & $\mathbf{s} / \mathbf{b}$ & $\mathbf{c} / \mathbf{b}$ & & $\mathbf{s} / \mathbf{b}$ & $\mathbf{c / b}$ \\
\hline 0 & 47,30 & 81,80 & & 97,10 & 91,05 \\
15 & 41,85 & 78,00 & & 95,45 & 90,00 \\
30 & 40,80 & 77,75 & & 95,40 & 91,40 \\
\hline
\end{tabular}

$\mathrm{c} / \mathrm{b}=$ com branqueamento; $\mathrm{s} / \mathrm{b}=$ sem branqueamento.

componentes cromóforos (sendo o principal a lignina) da polpa celulósica com a utilização de diversos tipos de reagentes, em sua maioria compostos oxidantes que conferem maior alvura (Segura et al., 2010). No caso da utilização para escrita e impressão, segundo Silva (2011), quanto mais opaco menos transparente é o papel, qualidade essa que permite uma melhor impressão em suas faces. Essa propriedade está fortemente influenciada pela elevada concetração de fibras que dificultam a passagem dos feixes de luz, aumentando a refração e reflexão da luz sobre a folha de papel.

De acordo com Santos (2005), a opacidade e a densidade básica da madeira são diretamente proporcionais e, quando são altas, a flexibilidade e a conformidade são reduzidas, consequentemente haverá maiores espaços vazios, que afetam diretamente o peso específico, porosidade e opacidade. Fibras com maior espessura de parede e maior densidade, no caso da Acácia-negra, apresentam dificuldade de refino e desfavorecem ligações entre fibras. Isso pode ter resultados positivos quando se pretende produzir papéis com alta opacidade ou volume específico (Wehr, 1991).

Nas avaliações com polpa c/b refinada com A. mearnssi de 6 anos e densidade de $516 \mathrm{~kg} / \mathrm{m}^{3}$, Segura et al. (2010) obteve opacidade de $71 \%$. Fang et al. (1991), investigando diversas variedades de Acácia-negra de climas tropicais e temperados, obteveram para $A$. Mearnssi de 10 anos e densidade de $608 \mathrm{~kg} / \mathrm{m}^{3}$ opacidade de $74,8 \%$ (ISO) para polpa refinada $\mathrm{c} / \mathrm{b}$.

Em relação a alvura, Busnardo et al. (1986) avaliaram os efeitos da temperatura e da carga alcalina na polpação de $A$. mearnssi de 7 e de 10 anos e explicam que a carga alcalina produz respostas mais rápidas para se obter maior alvura na polpa. Em seu estudo obtiveram alvura de 28,6\% (ISO) e 26,2\% (ISO) para polpa s/b sem refino com Kappa de18,68 e 22,53, respectivamente. Para a mesma espécie com 6 anos, Segura et al. (2010) obteve, em polpas refinadas $\mathrm{c} / \mathrm{b}$, alvura de $45,1 \%$ e $42,3 \%$ (ISO), com Kappa de 15,2 e 18,1, respectivamente. Segundo Foelkel (2008), a espécie A. mearnsi tem índice médio de alvura em polpa s/b em torno de $43 \%$ (ISO) com Kappa de 9.

Analisando e correlacionando os resultados das Tabelas 6 e 7 é possível verificar valores superiores aos de Busnardo et al. (1986) para polpa s/b e sem refino e de Segura et al. (2010) para o índice de alvura nas polpas c/b com refino. De modo geral é possível concluir que o efeito do refino afetou mais negativamente, nos índices de alvura, na polpa s/b do que na polpa c/b.

Foelkel (2008) e Clarke et al. (2009) afirmam que pelas propriedades apresentadas, de maneira geral, as polpas branqueadas de $A$. mearnsii são materias-primas adequadas para a fabricação de papéis tipo tissue e absorvente, cuja maciez merece destaque, além de outros tipos, como decorativos, filtros, embalagens, cartões multicamadas etc.

\section{CONCLUSÕES}

Após avaliações realizadas na composição química da madeira da Acacia mearnsii De Wild foi possível constatar baixas concentrações de lignina e extrativos, substâncias que afetam no rendimento da polpa, o que resulta em economia no consumo de produtos químicos para cozimento e branqueamento.

Constatou-se um rendimento regular decorrente das características anatômicas das fibras e pela maior densidade básica nessa espécie, que acabam dificultando a impregnação dos cavacos. Contudo, obtiveram-se baixos índices de lignina residual (Kappa) na polpa sem refino, tanto no final do cozimento como após o primeiro branqueamento. Isso denota a eficiência do cozimento e, portanto, uma redução no consumo de produtos para cozimento e branqueamento.

Com base nos resultados das análises físicas realizadas nas folhas de papel com polpas refinadas e não refinadas, branqueadas e não branqueadas, foi possível concluir que não houve alterações significativas nas propriedades físicas (espessura, densidade e volume aparente). Verificou-se apenas um pequeno decréscimo de espessura e volume específico com o refino.

Nas propriedades mecânicas (tração, rasgo e estouro), nas folhas formadas com polpa c/b e s/b, de 
modo geral, houve um aumento significativo advindo do refino.

Em relação às propriedades ópticas (alvura e opacidade) das folhas formadas com polpas s/b e c/b, com e sem refino, obtiveram-se índices superiores se comparados aos relatados na literatura. Pelos resultados apresentados é possível concluir que folhas $\mathrm{c} / \mathrm{b}$ e s/b diminuem suas propriedades ópticas com o refino.

Pelas características gerais que os resultados desta pesquisa apresentaram é possível indicar a polpa da espécie $A$. mearnsii como matéria-prima ideal para produção de papéis do tipo tissue e absorventes. Contudo, com adequações no seu processamento pode-se ampliar a sua aplicação como matéria-prima para outros tipos de papéis.

\section{AGRADECIMENTOS}

Os autores agradecem ao Laboratório de Polpa e Papel - DETF.

\section{STATUS DA SUBMISSÃO}

Recebido: 2 jun., 2014

Aceito: 22 mar., 2016

\section{AUTOR(ES) PARA CORRESPONDÊNCIA}

\section{Nelson Potenciano Marinho}

Departamento de Design, Centro Universitário Autônomo do Brasil - UniBrasil, Rua Konrad Adenauer, 442, Tarumã, CEP 82821-020, Curitiba, PR, Brasil

e-mail: nelsonmarinho@unibrasil.com.br

\section{REFERÊNCIAS}

Associação Brasileira de Produtores de Florestas Plantadas - ABRAF. Anuário estatístico ABRAF 2013 ano base 2012. Brasília; 2013. 148 p.

Balodis V. Planning of pulpwood production from plantations. In: Turnbull JW. Advanced in tropical acacia research. Canberra: ACIAR; 1991. p. 132-137.

Biermann C. Handbook of pulping and papermaking. 2. ed. San Diego: Academic Press; 1996. 754 p.

Boland DJ, Brooker MIH, Chippendale GM, Hall N, Hyland BPM, Johnston RD et al. Forest trees of Australia. Melbourne: Nelson-CSIRO; 1984.
Busnardo CA, Gonzaga JV, Sansigolo CA. Caracterização da qualidade da madeira e da celulose kraft produzida a partir de árvores de $A$. mearnsii sadias e atacadas por gomose. Silvicultura 1986; 11(41): 194.

Caldeira MVW, Neto RMR, Schumacher MV, Watzlavick LF. Exportação dos nutrientes em função do tipo de exploração em um povoamento de Acacia mearnsii DE WILD. Revista Floresta e Ambiente 2002; 9(1): 97-104.

Clarke B, McLeod I, Vercoe T. Trees for farm forestry: 22 promising species. Canberra: RIRDC; 2009. RIRDC Publication n. 06/015.

Costa J A. Qualidade da madeira de Eucaliptus urograndis, plantado no distrito federal, para produção de celulose Kraft [dissertação]. Brasília: Departamento de Engenharia Florestal, Universidade de Brasília; 2011.

D’Almeida MLO. Celulose e papel: tecnologia de fabricação da pasta celulósica. 2. ed. São Paulo: SENAI-IPT; 1988.

Da Rosa CAB. Influência do teor de lignina da madeira de Eucalyptus globulus na produção e na qualidade da celulose Kraft [dissertação]. Santa Maria: Centro de Ciências Rurais, Universidade Federal de Santa Maria; 2003.

Fang G, Wang J, Balodis V, Clark NB. Kraft pulping properties of A.mearnsii and A.silvestri. In: Turnbull JW, editor. Advances Tropical Acacia Research. Canberra: ACIAR; 1991. p. 145-150. Proceedings, n. 35.

Ferreira P. Propriedades do papel: ciência e tecnologia da pasta do papel. Coimbra: Departamento de Engenharia Química, Faculdade de Ciências e Tecnologia, Universidade de Coimbra; 2008.

Foelkel C. Propriedades papeleiras das árvores, madeiras e fibras celulósicas dos eucaliptos. Eucalyptus Online Book \& Newsletter; 2009.

Foelkel CEB. Estrutura da madeira: curso de fabricação de celulose. Associação Técnica Brasileira de Celulose e Papel; 1993. 82 p.

Foelkel CEB. Os eucaliptos e as leguminosas: parte 01: Acacia mearnsii. Eucalyptus Online Book \& Newsletter; 2008.

Fowler JAP, Curcio GR, Rachwal MFG, Dedecek RA, Simon AA. Germinação e vigor de sementes de Acacia mearnsii De Wild coletadas em diferentes povoamentos do Estado do Rio Grande do Sul. Colombo: Embrapa/ Florestas; 1999. 4 p. Comunicado Técnico n. 39.

International Organization for Standardization - ISO. ISO 5264-3: laboratory beating: part 3: Jokro mill method. Geneva; 1979. 10 p.

International Organization for Standardization - ISO. ISO 5267-1: determination of drainability: part 1: SchopperRiegler method. Geneva; 1999. 7 p.

Klock U. Qualidade da Madeira Juvenil de Pinus Maximinoi H. E.Morre [tese]. Curitiba: Setor de Ciências Agrárias, Universidade Federal do Paraná; 2000. 
Manfredi M. Desenvolvimento de propriedades de papéis reciclados por tratamento ultrassônicos e adição de xilanas [dissertação]. Viçosa: Setor de Ciências Florestais, Universidade Federal de Viçosa; 2010.

Martinez DT. Seleção genética de acacia mearnsii de wild. (acácia-negra) visando o aumento da qualidade e produtividade de madeira e tanino no Rio Grande do Sul [dissertação]. Curitiba: Setor de Ciências Agrárias, Universidade Federal do Paraná; 2006.

Martins MAL. Estudo Tecnológico da polpação Kraft de Acacia mearnsii DE Wild [dissertação]. Viçosa: Setor de Ciências Florestais, Universidade Federal de Viçosa; 1983.

Nevell TP, Zeronian SH. Cellulose chemistry and its application. New York: John Wiley \& Sons; 1985.

Petrik AW, Busnardo CA, Gonzaga JV, Milanez AF. Produção de celulose kraft a partir de misturas de madeiras de Eucalyptus saligna e Acacia mearnsii. In: Anais do Congresso Anual da ABTCP; 1984; São Paulo. São Paulo; 1984. p. 297-324. v. 17.

Resende MDV. Workshop sobre Melhoramento de Espécies Florestais e Palmáceas no Brasil. In: Resende MDV, Rezende GDSP, Demuner B. Utilização de espécies do gênero Acacia na produção de celulose de fibras curtas no sudoeste Asiático e na África. Colombo: Embrapa Floresta; 2001. p. 16-39. Documentos, n. 62.

Sanjuan DR. Obtención de pulpas y propiedades de las fibras para papel. Guadalajara: Departamento de Celulosa y Papel, Universidade de Guadalajara; 1997. 293 p.

Sansigolo CA, Busnardo CA, Gonzaga JV. Qualidade de madeira e polpa de árvores jovens e adultas de Acacia mearnsii. In: Congresso Anual da ABTCP; 1986; São Paulo. São Paulo; 1986. p. 51-77. v. 19.

Santos SR. Influência da qualidade da madeira de híbridos de Eucalyptus grandis $x$ Eucalyptus urophylla e do processo Kraft de polpação na qualidade da polpa branqueada [dissertação]. Piracicaba: Setor Recursos Florestais, Escola Superior de Agricultura Luiz de Queiroz; 2005.
Scott WE, Abbott JC, Trosset S. Properties of paper: an introduction. 2. ed. Atlanta: Tappi Press; 1995. 191 p.

Segura TES, Zanão M, Da Silva FG Jr. Potencial da Madeira de acácia para a produção de polpa celulósica Kraft. In: XXI Encontro Nacional da TECNICELPA / VI CIADICYP; 2010; Lisboa. Lisboa; 2010.

Segura TES. Avaliação das madeiras de Eucalyptus grandis $x$ Eucalyptus urophylla e Acacia mearnsii para produção de celulose Kraft pelos processos convencional e Lo-Solids ${ }^{\circledast}$ [dissertação]. Piracicaba: Setor de Tecnologia de Produtos Florestais. Escola Superior de Agricultura Luiz de Queiroz; 2012.

Seiger DS. Economic potential from Western Australian Acacia species: secondary plant products. Conservation Science 2002; 4(3): 109-116.

Silva MG. Produtividade, idade e qualidade da madeira de Eucalyptus destinada à produção de polpa celulósica branqueada [dissertação]. Piracicaba: Setor de Tecnologia de Produtos Florestais, Escola Superior de Agricultura Luiz de Queiroz; 2011.

Silva R, Haraguchi SK, Muniz EC, Rubira AF. Aplicações de fibras lignocelulosicas na química de polímeros e compósitos. Química Nova 2009; 32(3): 661-671. http:// dx.doi.org/10.1590/S0100-40422009000300010.

Stein FR. Modelagem de produção industrial de celulose Kraft com modelos aditivos generalizados e redes neurais [dissertação]. Curitiba: Setor de Tecnologia de Celulose e Papel, Universidade Federal de Viçosa; 2010.

Technical Association of Pulp and Paper Industry - TAPPI. Standart test methods: 2004-2005. Atlanta, 2005. CD-ROM.

Wehr TFA. Variações nas características da Madeira de E. grandis Hill ex-maiden e suas influências na qualidade de cavacos em cozimento Kraft [dissertação]. Piracicaba: Setor de Recursos Florestais, Escola Superior de Agricultura Luiz de Queiroz; 1991. 